\title{
A cultura boliviana na escola e o "fazer especial" como ampliação e descolonização da experiência estética
}

Francione Oliveira Carvalho ${ }^{1}$

\begin{abstract}
RESUMO: Em um mundo aberto à circulação do capital, mas não das pessoas, as que migram em busca de melhores condições econômicas e sociais precisam vencer tanto os percalços inerentes ao processo migratório como a hostilidade de muitas comunidades que as recebem e, muitas vezes, as rejeitam. Situações de discriminação e intolerância que diminuem e não reconhecem a humanidade do Outro. A educação infantil e a primária não estão imunes a esta questão, portanto, este trabalho discute as ações realizadas em duas escolas municipais da cidade de São Paulo na promoção da diversidade e do reconhecimento das tradições culturais sul-americanas com destaque para as de origem boliviana. A partir da pergunta: "O que você aprendeu com os seus pais?", as crianças das escolas apresentadas levaram objetos, imagens, álbuns de fotografias, comidas, roupas, danças e compartilharam tradições, memórias e fazeres que possibilitaram experiências estéticas que ampliaram os territórios da arte e da cultura. Palavras-chave: Interculturalidade. Cultura boliviana. São Paulo. Escola. Fazer especial.
\end{abstract}

The Bolivian culture in the school and the "making special" as the expansion and decolonization of the aesthetic experience

ABSTRACT: In a world open to the movement of capital, but not of people, those who migrate in search of better economic and social conditions must overcome both the inherent obstacles to the migratory process and the hostility of communities that receive them and often reject them. Situations of discrimination and intolerance that diminish and do not recognize the humanity of the Other. Early childhood and primary education are not immune to the issue, motivating this paper. Here we discuss the actions taken in two municipal schools in the city of São Paulo to promote diversity and to recognize South American cultural traditions, especially those of Bolivian origin. Starting with the question: "What have you learned from your parents?", the children of the schools presented objects, images, photo albums, foods, clothes, dances and shared traditions, memories and practices that enabled aesthetic experiences that expanded the territories of art and culture.

Keywords: Interculturality. Bolivian culture. São Paulo. School. Making special.

\section{INTRODUÇÃO}

A escola enquanto instituição social é um

${ }^{1}$ Doutor e Mestre em Educação, Arte e História da Cultura pela UPM, Pós-Doutorado em História pela FFL$\mathrm{CH} /$ USP. Professor da Faculdade de Educação da UFJF, coordenador da Especialização em Ensino de Artes Visuais CEAD/UFJF e Líder do MIRADA - Grupo de Estudo e Pesquisa em Visualidades, Interculturalidade e Formação Docente. É colaborador do Programa de PósGraduação em Humanidades, Direitos e Outras Legitimidades da USP. Contato: francioneoliveiracarvaIho@gmail.com dos espaços privilegiados de formação em que a aprendizagem dos saberes deve estar relacionada ao cotidiano dos alunos desde o aspecto local ao global. Assim, a escola, além de possibilitar aos alunos à apropriação dos conteúdos de maneira crítica e construtiva precisa valorizar a cultura e a arte de sua própria comunidade, contribu- 
indo para o exercício de cidadania e de pertencimento cultural.

Durante meu estágio de Pós-Doutoramento no Diversitas: Núcleo de Estudos das Diversidades, Intolerâncias e dos Conflitos da Universidade de São Paulo durante os anos de 2015 e 2016, investiguei como as escolas da rede municipal da cidade de São Paulo lidavam com as demandas da imigração sul-americana, principalmente a boliviana, já que nos últimos anos cresceu o número destes imigrantes na metrópole.

Desde a implementação do Mercosul vemos o fluxo de imigrantes sul-americanos aumentar tanto nas regiões de fronteiras como nas grandes cidades brasileiras, caso da capital paulista. A situação econômica de seus países de origem e a possibilidade de trabalho e mobilidade social fazem com que muitos imigrantes sejam atraídos para São Paulo. A imigração boliviana como diversos estudos apontam não é algo novo no Brasil.

O ponto de partida foi a década de 1950 devido a um programa entre Brasil e Bolívia que beneficiava estudantes bolivianos que vinham para o território brasileiro em busca de qualificação acadêmica. Entretanto é a partir da década de 1970 que a migração boliviana e de outros países da América do Sul torna-se uma constante, intensificada, no caso da Bolívia, a partir de 1985. A impressão de que a imigração boliviana é algo recente ocorre porque nos últimos anos ela se acelerou. O Consulado da Bolívia estima que a população total no Brasil seja em torno de 350 mil imigrantes, sendo $75 \%$ residentes na região metropolitana de São Paulo. Entretanto outros órgãos como o Centro de Estudos Migratórios acreditam que há em São Paulo aproximadamente 500 mil imigrantes bolivianos.

A imigração boliviana no território brasi- leiro caracteriza-se por uma forte concentração em poucos lugares. Souchard (2012) afirma que no caso de São Paulo a distribuição dos migrantes é desigual, mas que atinge todas as áreas do perímetro urbano do município, alcançando a região metropolitana de São Paulo, principalmente em Guarulhos, Osasco e Diadema. Do total de bolivianos que vivem na região metropolitana de São Paulo, 19,5\% estão na região central da capital nos bairros do Bom Retiro, Pari, Canindé, Belém e Brás. Nessas áreas, eles dividem espaço com outros grupos, como coreanos, judeus, poloneses e outros migrantes da América do Sul. O que não acontece nas outras regiões, Souchard (2012) ainda aponta que em Guarulhos e na região sul da capital eles representam quase $100 \%$ do total de imigrantes e possuem pouco tempo de residência, contrário da região central onde possuem maior tempo de presença acumulada.

Ao olharmos especificamente para a educação, alguns dados comprovam a forte presença da comunidade boliviana no sistema educativo paulista. A Secretaria Estadual de São Paulo divulgou que em 2014, 8,5 mil estudantes nascidos em outros países se matricularam em escolas estaduais, sendo 5 mil alunos originários da Bolívia. Já na rede municipal de ensino paulistana, segundo dados oficiais atualizados de 2017, há 4.747 alunos estrangeiros matriculados nas escolas municipais, sendo 2.457 de bolivianos.

Conflitos e debates educacionais, culturais e políticos nascem desta nova realidade, assim, fronteiras simbólicas são erguidas e começam a delimitar as ações dos sujeitos envolvidos. Este artigo traz uma reflexão sobre a presença dos alunos estrangeiros na Rede Municipal de São Paulo, 
com destaque para os de origem boliviana matriculados na EMEF Infante Dom Henrique, na EMEF Anália Franco Bastos. Localizadas respectivamente nos bairros do Belém e do Canindé, regiões que concentram desde a década de 1990 os novos migrantes sul-americanos que aportam na cidade de São Paulo.

A disponibilidade em abrir a escola para o diálogo com a comunidade é um passo importante para o início de um trabalho efetivo de educação. Nesse contexto, vejo como bem-sucedidas as iniciativas das escolas em propor rodas de discussões com os alunos de origem migrante, suas famílias e a comunidade escolar como o reconhecimento e valorização de seus saberes e suas culturas de origem.

A EMEF Anália Franco Bastos foi criada em 1992 a partir de um antigo convênio entre a Secretaria Municipal de Educação e a Federação Espírita de São Paulo para atender as crianças provenientes das favelas do Benfica, Vila Maria e Nelson Cruz. Inicialmente instalada na Casa Transitória Fabiano de Cristo, em 2008, a escola muda para o endereço atual na região do Belém e começa a receber um número cada vez maior de famílias bolivianas, que totalizam hoje $40 \%$ dos alunos matriculados na instituição.

Já a EMEF Infante Dom Henrique, localizada no Canindé, foi criada em 1960, e tal como a EMEF Anália Franco Bastos atende uma comunidade escolar que convive com situações de vulnerabilidade. A escola é vizinha de uma favela e de diversos equipamentos sociais que atendem principalmente moradores de rua e que acolhem migrantes nacionais e internacionais. Um ponto a destacar é que a EMEF Infante Dom Henrique é próxima a Praça Kantuta, importante centro de socialização da comunidade boli- viana em São Paulo. Porém, o número total de alunos de origem estrangeira na instituição é menor que o da escola anterior, totalizando $14 \%$ dos alunos matriculados. A partir do Projeto Escola Apropriada: educação, cidadania e direitos humanos, desenvolvido entre 2014 e 2015, pretende-se refletir sobre as estratégias utilizadas no projeto para compartilhar e agregar às experiências culturais dos alunos imigrantes no dia a dia da instituição. Descolonizar o processo educacional significa liberá-lo, ou emancipá-lo, do monismo ocidentalista que reduz todas as possibilidades de saber e enunciação da verdade à dinâmica cultural de um centro. Esse movimento traz consigo igualmente a descolonização da crítica, não compactuando com a ideia de que o conhecimento é algo exclusivo do letrado ou que caberia a este último iluminar criticamente o Outro.

\section{DESCOLONIZANDO A EXPERIÊNCIA ESTÉ- TICA}

Trabalhar com a estética do cotidiano na escola é ampliar o conceito de arte para objetos e práticas que possibilitem experiências estéticas independente delas estarem inseridas na categoria que conhecemos como arte. Nesse contexto, a ideia de "fazer especial" desenvolvida pela antropóloga Ellen Dissanayake (1991) pode nos ajudar a expandir os territórios da arte e da cultura. A ideia do "saber único" termina recalcando uma parte importante da realidade porque há práticas sociais baseadas em conhecimentos populares, conhecimentos indígenas, conhecimentos camponeses, conhecimentos urbanos, mas que não são avaliados como importantes ou rigorosos. Muitas vezes, o conhecimento posto à margem do 
capital e, portanto, não legitimado pela ideologia cientificista da verdade é associado ao trabalho manual e culturalmente desqualificado.

A partir da descolonização, Boaventura de Souza Santos (2000) propõe a ecologia dos saberes, a possibilidade de que a ciência entre não como monocultura, mas como parte de uma ecologia mais ampla de saberes, em que o saber científico possa dialogar com o saber laico, com o saber popular e com as diversas formas de conhecimentos e tradições. Santos afirma que o importante não é ver como o conhecimento representa o real, mas conhecer o que determinado conhecimento produz na realidade e intervém nela. A crítica é um modo de aprender a ler a realidade sem a qual se afigura inócua toda a educação. Assim, a enunciação crítica está no cerne da aprendizagem pensada a partir da descolonização da educação, pois questiona a vigência do pensamento único e as explicações monoculturais do mundo, ou seja, uma civilização pensada no singular. A escola contemporânea deve ser vista como o tempo educacional da descolonização, da reinvenção dos sistemas de ensino, com vistas à diversidade e ao reconhecimento da pluralidade dos saberes e das experiências. O Projeto Escola Apropriada: educação, cidadania e direitos humanos ao trazer as culturas bolivianas para o centro do currículo caminha nessa direção e, portanto, será centralizado neste texto.

Os Parâmetros Curriculares Nacionais, que em 1997 elegeram a Pluralidade Cultural como tema transversal é o marco da discussão intercultural na escola brasileira. Em seguida, vimos a publicação do Referencial Curricular Nacional para as Escolas Indígenas (1998) e a promulgação da Lei 10.639/03 que trouxe a obrigatoriedade do ensino sistemático de História e Cultura Afro-brasileira e Africana, e em 2008 a Lei 11.645 que problematiza a História e Culturas Indígenas.

Tanto a Lei 10.639/03 quanto a $11.645 / 08$ nos motiva a refletir sobre como ocorrem as mediações culturais nos primeiros anos escolares e quais caminhos educativos são percorridos na tentativa de valorizar e compreender as diversidades. A mediação deve ser compreendida como um encontro, mas não como nenhum encontro. Um encontro sensível, atento ao outro, com qualidade e intensidade, para ampliar conexões possíveis e uma interação especial afetando alunos, educadores e a comunidade como um todo. A arte por si só provoca encontros, entretanto, a mediação pode encontrar brechas de acesso para que esse encontro possa ser realizado.

Mesmo amparado em documentos legais a questão da diversidade e da mediação cultural encontra grandes desafios na escola brasileira. Duas razões são cruciais, a primeira a multiplicidade de pertencimentos étnico-raciais presentes nas salas de aula, resultado do processo histórico do país, das diversas ondas migratórias e recentemente da chegada de refugiados fugindo de conflitos armados ou outras violações dos direitos humanos. A outra razão como já apontado em texto anterior (CARVALHO, MARTINS, 2014) é que os cursos de formação docente para os primeiros anos do Ensino Fundamental dão pouco espaço para as questões culturais e ignoram abordagens do patrimônio cultural material e imaterial que poderiam ampliar mediações interculturais.

A partir da pergunta: "O que você aprendeu com os seus pais?" Os alunos de origem boliviana da EMEF Infante Dom Henrique 
levaram objetos, imagens, álbuns de fotografias, comidas, roupas, danças e compartilharam tradições, memórias e fazeres em diversos momentos do cotidiano escolar. Trocas intergeracionais entre alunos do primeiro e do segundo ciclo e a presença das famílias na escola ampliaram o alcance das descobertas e experiências.

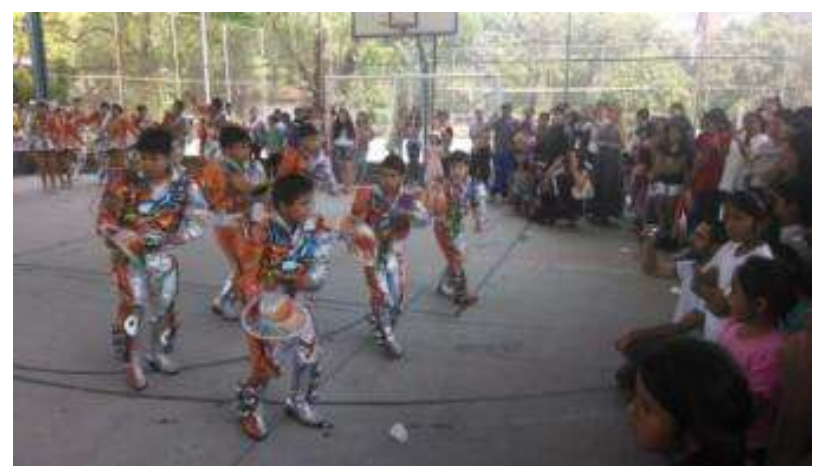

Figura 1. Grupo Folclórico Kantuta Bolívia se apresentando na Festa Junina de 2014 na EMEF Anália Franco Bastos em São Paulo.

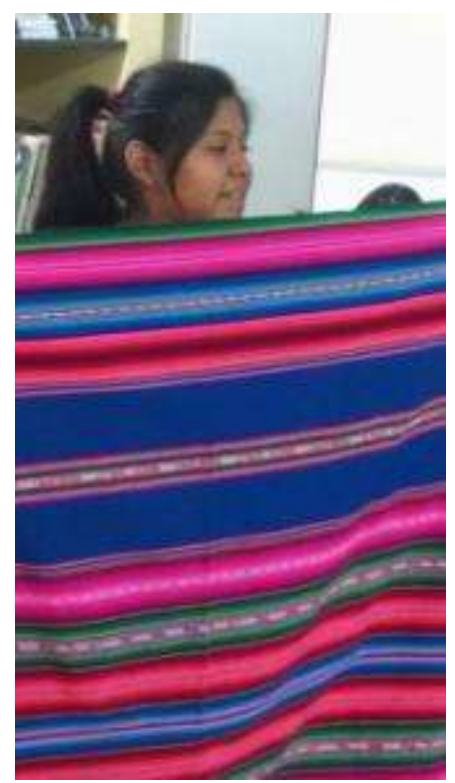

Figura 2. A aluna Aline Calle Quispe do II Ciclo da EMEF Infante Dom Henrique compartilha com os alunos menores os diversos usos dos tecidos andinos.

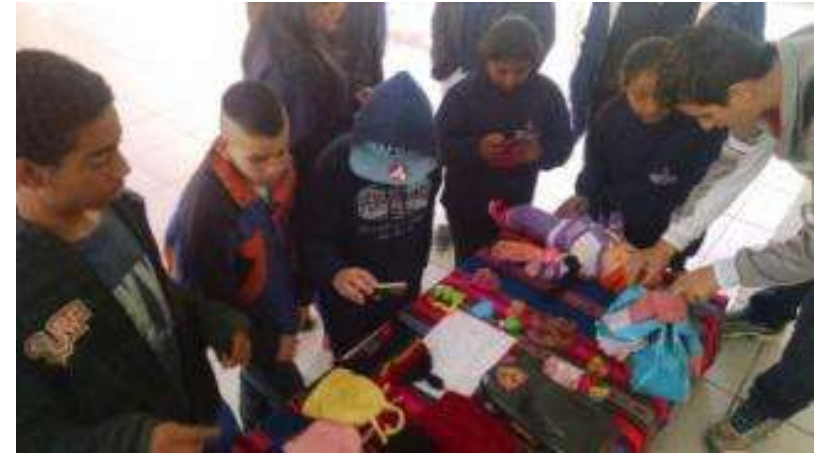

Figura 3. Alunos da EMEF Infante Dom Henrique compartilham com os colegas brinquedos e objetos que trouxeram ou ganharam de parentes que viajaram para a Bolívia (Registros do pesquisador).

Dentro de um território com tantas urgências e demandas como é a escola, como conseguir olhar de forma atenta para a diversidade? Como não se deixar automatizar pelo cotidiano, fechando os olhos para a vida que pulsa nela? A professora de Arte da escola Maria de Fátima que propõe diversos trabalhos a partir das corporeidades e visualidades dos alunos narra uma passagem ocorrida na sala de aula a esse respeito.

Numa aula estava trabalhando sobre cores. Aí um aluno fala assim: "professora, será que você me empresta o lápis cor de pele?". Aí eu perguntei, "cor da pele de quem?". "Esse aqui professora. " "Não, essa cor se chama salmão", então, durante o nosso trabalho de identidade aproveitei esse gancho para discutir as diferenças. Os bolivianos começaram a perceber, que eles têm características físicas diferentes, e que o diferente é bacana e que deve ser respeitado. Então, toda vez que eles me trazem, qualquer coisa que seja, como a fala: "ah professora, mas oIha, os cabelos deles são lisos. Eu digo "Tudo bem os cabelos deles são lisos. 0 meu é ondulado e faço chapinha porque eu gostaria que o meu fosse liso". Então, cada uma das diferenças que eles trazem, 
a gente compara e coloca no todo. Uma das meninas me falou que ela já tem algum contato com confecção, porque eles vêm para trabalhar nas confecções aqui do bairro. Falei: "é mesmo? Então, na próxima aula você vai me trazer alguma coisa que você tenha feito. " E ela me trouxe uma calça, me trouxe uma blusa. No momento em que ela trouxe dentro de sala, a gente pode comparar cor, textura porque a minha aula é de arte. Como é que ela chegou naquilo? O que ela quer fazer da vida dela? E a partir do momento em que ela se abriu, um monte de gente se sentou e falou, "ah, mas meu pai também faz isso", "olha minha mãe também faz", "professora, já fiz uma blusa", "olha professora, essa blusa foi eu que fiz". Então é assim, cada vez que a gente trabaIha, a gente abre ainda mais o leque para eles todos. (Maria de Fátima Martinho Betoletti em depoimento gravado em 05/09/2013).

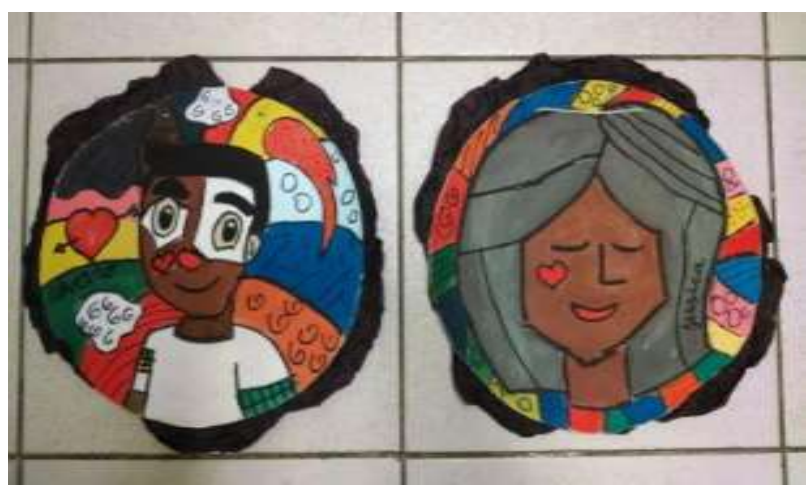

Figura 4. Trabalhos realizados pelos alunos sob a orientação da professora Maria de Fátima Martinho Betoletti onde destacamse características físicas dos alunos de origem boliviana (Registro do pesquisador).

O relato da professora revela um dado constante, o de que a grande maioria das famílias de origem boliviana que residem em São Paulo e região metropolitana trabaIham informalmente na indústria têxtil e no mercado varejista de apelo popular. Algumas famílias, depois de um tempo, conse- guem fundar suas próprias oficinas de costura e trazem novos membros da Bolívia para o Brasil. A cobrança na rapidez das encomendas faz com que fiquem sujeitos a grandes cargas horárias de trabalho diário, restando para as famílias pouco tempo de lazer, socialização e uso dos aparelhos culturais da cidade. Pensando nisso, a EMEF Infante Dom Henrique criou, com a ajuda dos alunos, um guia cultural com informações sobre os equipamentos públicos e privados próximos da escola a partir das seguintes categorias: escolas, esportes, cultura e lazer, museus, saúde e cuidados com a natureza. Incentivando também saídas coletivas para o reconhecimento do entorno escolar.

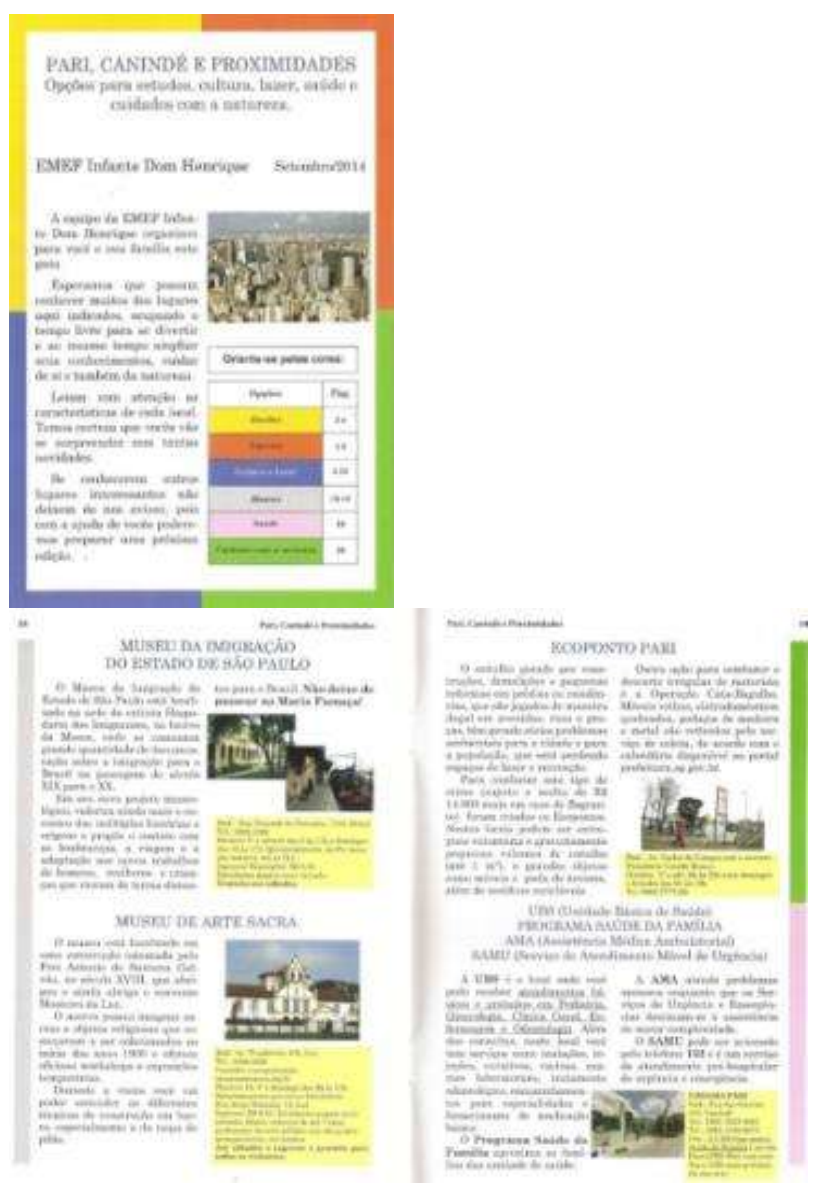

Fig. 5. Produção de guia cultural com os equipamentos públicos e privados próximos da escola a partir das seguintes categorias: escolas, esportes, cultura e lazer, museus, saúde e cuidados com a natureza. 


\section{EXPEDIÇÃO BOLÍVIA}

No segundo semestre de 2014 um estudo de campo na Bolívia arcado pela Secretaria Municipal de Educação de São Paulo torna-se realidade. A delegação foi composta por 17 pessoas, entre alunos brasileiros e de origem estrangeira, professores e equipe gestora. A escolha dos alunos que participaram da viagem foi feita através de votação entre os participantes do projeto.

A viagem foi realizada entre os dias $14 \mathrm{e}$ 19 de outubro de 2014 e, nesse período, os alunos puderam conhecer e vivenciar a cultura boliviana a partir de sua gente, de sua cultura material e da sua natureza. A partir dessa imersão na cultura, na história, na geografia e no cotidiano da população de La Paz, almejava-se incorporar os conhecimentos vivenciados pelo grupo no currículo e nos projetos da escola no ano de 2015 . Os desdobramentos da expedição são sentidos até hoje, três anos após a viagem, e resultam em diversas outras ações pedagógicas e culturais. No roteiro da expedição destacamos a visita à Praça Murillo, ao Palácio presidencial e o Senado, ao Museu Nacional de Arte, ao Museu Folclórico e Etnográfico de La Paz, ao teleférico de La Paz e à cidade de El Alto, ao sítio arqueológico de Tiwanaku e ao Lago Titicaca, além de reuniões com a Diretoria Geral de Educação de La Paz e visitas às escolas México e Santa Rosa de La Florida, localizadas na capital boliviana.

No retorno da viagem os integrantes da Expedição Bolívia apresentaram para a escola os registros e as percepções sobre a viagem. Alguns selecionaram imagens e editaram pequenos vídeos compartilhando com o grupo um pouco da experiência vivida. Nos depoimentos algumas frases chamaram atenção não apenas pelo conteúdo, mas pela recorrência nas falas: "Não imaginava que a Bolívia tivesse uma cultura tão rica", "Os bolivianos têm orgulho da Bolívia, diferentes de nós em relação ao Brasil", "A gente não sabe nada sobre nossos países vizinhos", "Por que é tão difícil olhar para um país e para as pessoas além dos estereótipos?", "Não podemos minimizar as culturas", "Isso que estou mostrando será trabaIhado no ano que vem em sala de aula", "Eu achava que conhecia a Bolívia, pois já fui muitas vezes lá, mas fiquei até com vergonha: Tudo era novo pra mim".

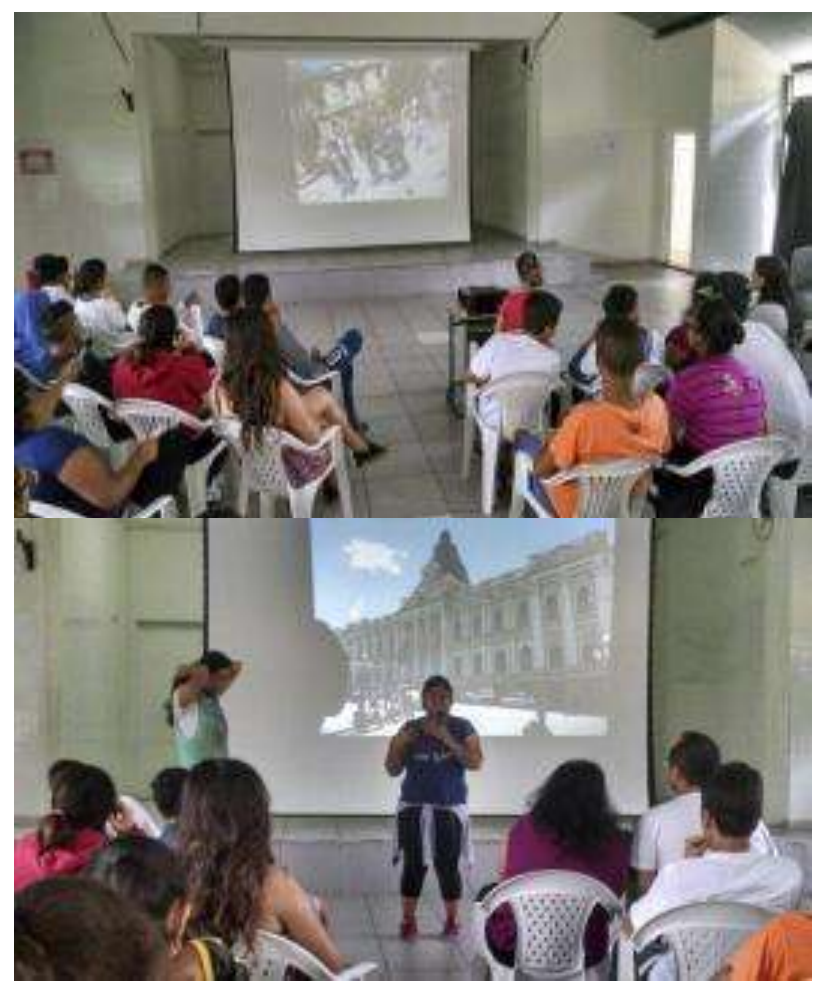

Figura 6. Alunos reunidos no pátio da escola para a socialização dos relatos sobre a Expedição Bolívia. Figura 7. A aluna Aline Calle Quispe contando sobre a experiência. (Registros do pesquisador.

Ainda como resultado desta pesquisa foi lançado, no ano de 2015, o documentário Escola Apropriada: Educação, Cidadania e Direitos Humanos que registra os 18 meses de pesquisa na EMEF Infante Dom Henrique e as ações do projeto Escola Apropriada. O 
mesmo foi direcionado a integração dos alunos estrangeiros matriculados na instituição e a criação de um currículo intercultural que culminou numa viagem de parte da equipe docente e discente ao território boliviano em busca de informações e materiais para serem aproveitados ao novo currículo escolar.



Fig. 8. Capa do documentário Escola Apropriada: Educação, Cidadania e Direitos Humanos (2015), direção de Francione Oliveira Carvalho, produção DIVERSITAS/USP .

Disponível

https://www.youtube.com/watch?v=PfKi69IASR0, acesso 20/02/2018.

\section{CONSIDERAÇÕES FINAIS}

Nas escolas brasileiras há um silenciamento sobre a arte e a cultura dos países da América do Sul pois a narrativa predominante ainda é a da civilização europeia. A origem do migrante determina o imaginário e o tratamento que ele receberá no país criando a figura do "bom" e do "mau" migrante. Bolivianos, haitianos e africanos não são vistos da mesma forma que europeus e americanos, criando situações diferenciadas no espaço público. Diversas pesquisas empíricas afirmam que a educação infantil e a primária não estão imunes desta questão e que a discussão da diversidade e dos direitos humanos devem estar presentes no cotidiano escolar desde cedo, afinal conviver com o diverso é um aprendizado constante. Cada escola é um território de fronteiras e bordas evanescentes que precisa aprender a construir significados conjuntos, assim a diversidade cultural e a imigração possibilitam significativas possibilidades de aprendizagem mútua, e a arte e a cultura estratégias de mediação e de construção de conhecimentos.

A educação assim como a arte é uma área de conhecimento que por natureza lida com a diversidade e a provocação, questionando e ampliando nossas percepções sobre o humano. Por refletir o nosso tempo, a arte contemporânea pode ser um território fértil e mobilizador para a discussão de temas cruciais, tais como a migração, o acirramento das fronteiras e a intolerância.

O artista japonês Yanagi Yukinori criou uma série de obras que discutem o tema das fronteiras e das migrações, das quais uma das mais conhecidas é Mercosul (2011). A discussão sobre materialidade, impermanência, fruição e política são temas da arte contemporânea presentes na obra Mercosul. $\mathrm{O}$ artista defende a ideia de que atualmente, devido à globalização, os limites geográficos devem ser questionados. Para ele, há uma contradição na nossa sociedade. Ao mesmo tempo que existe um incentivo à livre circulação de produtos e serviços entre os países, há um enrijecimento das regras que permitem que as pessoas circulem entre eles.

A obra é composta por caixas de acrílico, nas quais areias coloridas formam as bandeiras dos países que participam do bloco econômico que dá título ao trabalho acrescidas as bandeiras das Guianas, territórios também localizados na América do Sul. Elas são conectadas por tubos de plástico, onde formigas cruzam os limites e misturam os 
grãos e as cores das bandeiras, criando pontes entre as nações e as culturas, fazendo uma relação direta com os movimentos migratórios na contemporaneidade e a ideia do Mercosul como território de livre circulação e integração cultural.

As formigas procuram trabalhar a ideia de erosão das fronteiras e questionar a integração cultural destes territórios. As Guianas são formadas por territórios que mesmo estando localizadas na América do Sul constituem países que não são integrados aos acordos econômicos e culturais da região, o que acaba por isolá-los. 0 processo de colonização diferenciado em relação aos outros países também interfere na relação.

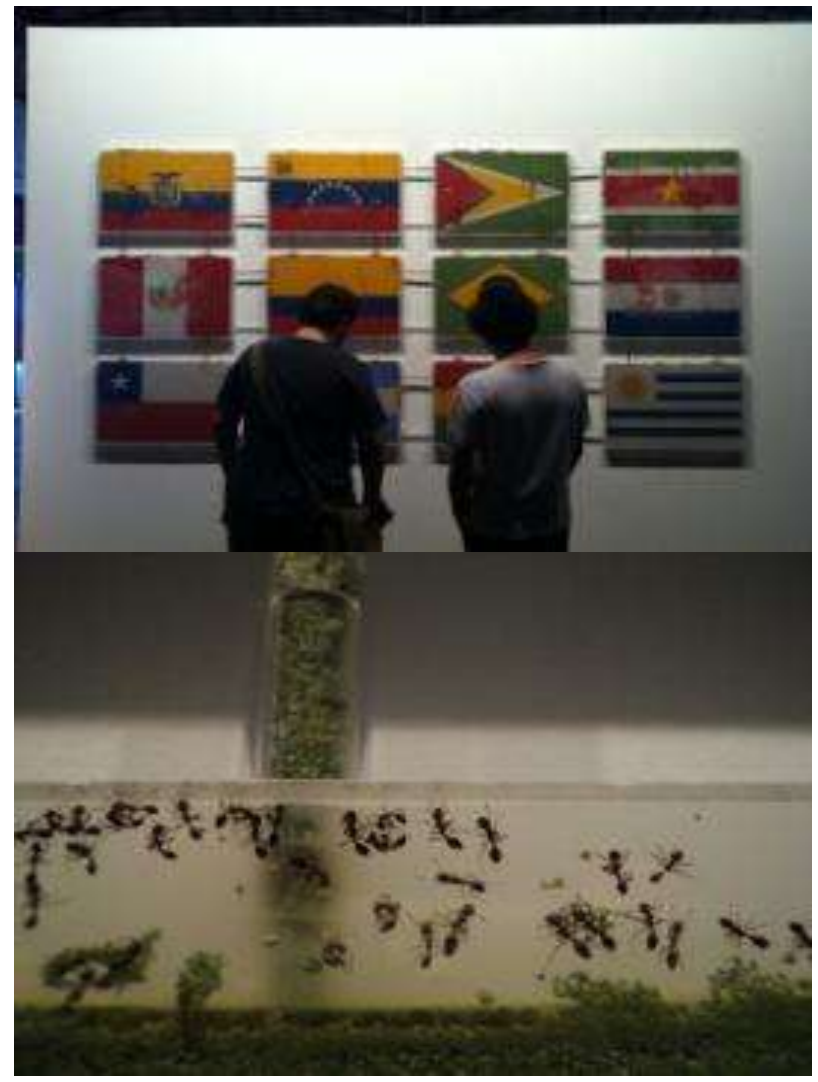

Figura 9. Mercosul (2011), de Yanagi Yukinori. Formigas, areia colorida, caixas, tubos e canos de plástico. $25 \mathrm{~cm} \times 36,5 \mathrm{~cm} \times 91$ $\mathrm{cm}$ (cada peça). Bienal do Mercosul, Porto Alegre, 2011. Imagem de divulgação.

A obra também nos ajuda a pensar no trabalho pedagógico, afinal professores são como formigas que realizam pequenas ações cotidianas que vistas isoladamente parecem imperceptíveis, mas que ao longo do tempo acumulam resultados importantes e transformadores. A ação única de um professor pode provocar alterações no cotidiano escolar, entretanto, é o trabalho parceiro e comunitário que constrói elos permanentes e solidários na escola.

Já a pungente instalação $E$ isto um homem? (2014) de Nuno Ramos exposta no Museu da Imigração de São Paulo retoma questão proposta por Primo Levi em 1958. Se naquela época o escritor italiano tentou na obra homônima superar os traumas de ter estado no campo de concertação de Auschwitz, durante a Segunda Guerra Mundial e compreender o incompreensível, hoje, o artista paulistano provoca reflexão sobre a violência e o desamparo a que tantos migrantes estão expostos.

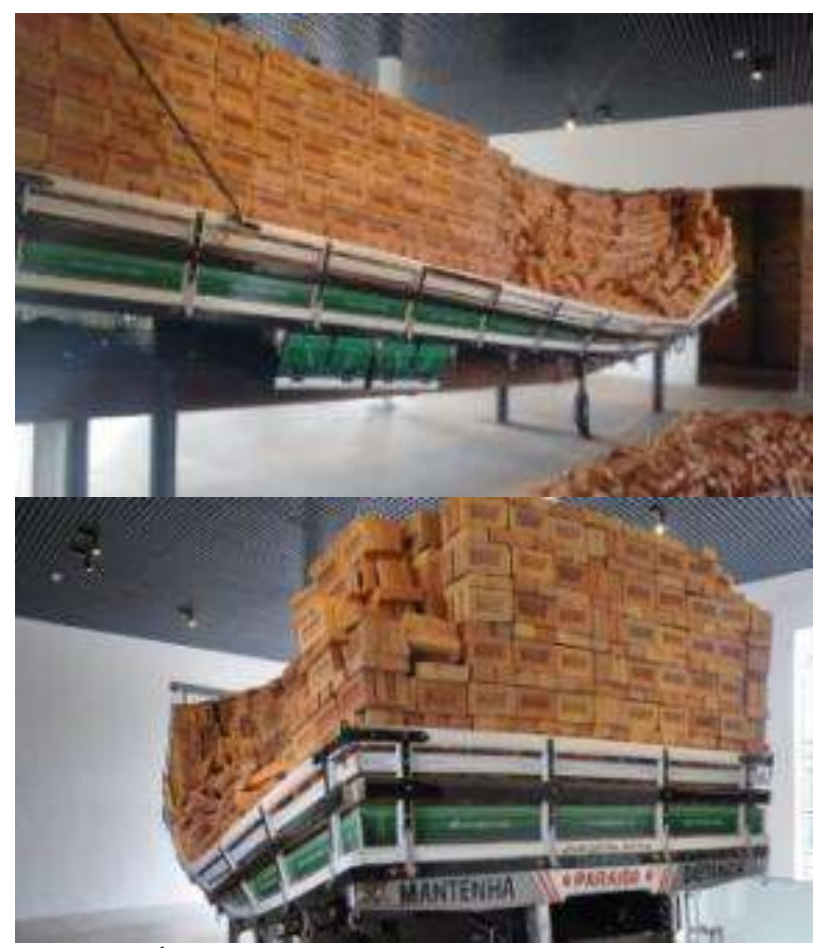

Figura 10. É isto um homem? (2014), de Nuno Ramos. Vista da exposição no Museu da Imigração, São Paulo. Imagem de divulgação. 
Num mundo tão pouco solidário, hostil e indiferente ao outro é fundamental que a escola não se omita de seu papel de socializar e humanizar as pessoas. Vidas perdidas pela violência e pelo ódio ou pelo fracasso na tentativa de ultrapassar barreiras e mares em busca de melhores condições de sobrevivência não podem se tornar apenas estatísticas ou imagens momentâneas nas redes sociais que causam furor e comoção seletiva e depois são substituídas e esquecidas. Como afirma Judith Butler (2015), sem a condição de ser enlutada, não há vida, pois apenas em condições nas quais a perda tem importância o valor da vida se efetiva. A condição de precariedade da vida deveria estar implicada nas relações sociais e na política porque todos estamos expostos e dependentes tanto àqueles que conhecemos quanto dos que não conhecemos.

Afirmar que a vida é precária é afirmar que a possibilidade de sua manutenção depende, fundamentalmente, das condições sociais e políticas, e não somente de um impulso interno para viver. [...] No entanto, o que talvez seja mais importante é que teríamos de repensar "o direito à vida" onde não há nenhuma proteção definitiva contra a destruição e onde os laços sociais afirmativos e necessários nos impelem a assegurar as condições para vidas vivíveis, e a fazê-lo em bases igualitárias. Isso implicaria compromissos positivos no sentindo de oferecer os suportes básicos que buscam minimizar a precariedade de maneira igualitária: alimentação, abrigo, trabalho, cuidados médicos, educação, direito de ir e vir e direito de expressão, proteção contra os maustratos e a opressão (BUTLER,2015).
É urgente que consigamos construir laços de solidariedade em defesa da vida digna, contra o desamparo e a violência. Ampliarmos a percepção das sociedades como circuitos de afeto, tal como propõe Safatle (2015), e recuperarmos a qualidade de sermos afetados pelas necessidades dos outros, percebendo-nos como mais uma vida que por ser precária precisa de amparo e proteção. Por que nos afetamos tão pouco pelas misérias e violências a que tantos são submetidos diariamente? Por que incorporamos o medo do outro nas nossas ações? Por que naturalizamos a exclusão? Hierarquizamos a vida? Os conhecimentos? Recuperar a dimensão do coletivo humano e das diversidades que a compõem em detrimento das individualidades e idiossincrasias parece difícil numa época onde nacionalismos extremos levam ao acirramento das fronteiras e ao desrespeito aos direitos humanos, entretanto, é imprescindível se quisermos defender vida justa e digna a todas as pessoas. Nenhuma categoria pode aprisionar a diversidade humana ou ser apropriada para minimizar ou impedir a circulação das pessoas. E toda escola que se propõe ser democrática e em defesa da vida deve não apenas defender esses valores, mas fomentá-los em suas ações, estimulando uma educação para a solidariedade, a cooperação e a sensibilidade.

\section{REFERÊNCIAS}

BUTLER, J. Quadros de Guerra: quando a vida é passível de luto? Rio de Janeiro: Civilização Brasileira, 2015.

CARVALHO, Francione Oliveira. MARTINS, Mirian Celeste. A interculturalidade na formação do pedagogo brasileiro: territórios de arte \& cultura. Revista Educação 
Online, n. 15, jan./abr. 2014, p. 144-157

DISSANAYAKE, Ellen. What is art for? Seatle, University of Washington Press, 1991.

SAFATLE, V. O circuito dos afetos: Vladimir Safatel. São Paulo: Cosac Naify, 2015.

SANTOS, Boaventura de Sousa. A crítica da razão indolente: Contra o desperdício da experiência. São Paulo: Cortez, 2000.

SANTOS, Boaventura de Sousa. Chauí, Marilena. Direitos humanos, democracia e desenvolvimento. São Paulo: Cortez, 2013.

SOUCHARD, Sylvain. A confecção: nicho étnico ou nicho econômico para a imigração latino-americana em São Paulo? in Imigração Boliviana no Brasil / Rosana Baeninger (Org.). - Campinas: Núcleo de Estudos de População-Nepo/Unicamp; Fapesp; CNPq; Unfpa, 2012. 